\section{Giant acquired acral fibrokeratoma: A case report}

\author{
Hend M. Al-Atif \\ Department of Internal Medicine, \\ College of Medicine, King Khalid \\ University, Abha, Saudi Arabia
}

\begin{abstract}
Acquired acral fibrokeratoma (AAF) is a rare benign fibrous tumor. Its size is usually small (i.e., $<0.5 \mathrm{~cm}$ ). However, few cases with giant lesions (i.e., $>1 \mathrm{~cm}$ ) have been reported. A 17-year-old Saudi male presented to the Dermatology Outpatient Clinic of Aseer Central Hospital, Aseer Region, Saudi Arabia, with a painless rounded skin-colored exophytic nodule arising from the dorsal surface of the right middle toe, $1.7 \mathrm{~cm}$ in diameter. The tumor was surgically excised. Histopathology examination revealed a giant polyploid lesion, composed of massive hyperkeratosis, acanthosis, a core of thick collagen bundles and vertically oriented small dermal blood vessels. The diagnosis was giant AAF. There was no evidence of recurrence after surgical excision. AAF is a rare benign skin tumor which should be differentiated from other similar skin lesions. Surgical excision is the first line for treatment.
\end{abstract}

\section{Introduction}

Acquired acral fibrokeratoma (AAF) is a rare benign fibrous tumor. It occurs as a solitary lesion, mainly in adults. ${ }^{1}$ Since its most frequent locations are the fingers and toes, it was commonly termed acquired digital fibrokeratoma (ADFK), although it may also affect the palms and the heels..$^{2,3}$ In cases with AAF, the size of the lesion is usually small (i.e., $<0.5 \mathrm{~cm}$ ). However, few cases with giant lesions (i.e., $>1 \mathrm{~cm}$ ) have been very rarely reported in the literature. ${ }^{4-8}$ The differential diagnosis for AAF includes garlic-clove fibroma, Bowen's disease, exostosis keloid, dermatofibrosarcoma, eccrine poroma, neurofibroma, corn (clavus), cutaneous horn, infantile digital fibromatosis, pyogenic granuloma, ungual and subungual fibroma, verruca, and supernumerary digit. ${ }^{9}$

ADFKs seem to have a slight male predominance. However, very few cases have been described to adequately assess the sig- nificance of any sex predilection of this tumor type. Reported acquired digital fibrokeratoma cases have occurred in patients from 12 to 70 years of age, with most cases occurring in middle-aged adults. ${ }^{10}$ Most patients with acquired digital fibrokeratoma present with an asymptomatic protuberance that gradually increases in size over time. ${ }^{11}$ Dupré et al. ${ }^{12}$ described this tumor entity is slightly prominent, well-defined, surrounded by a hyperkeratotic collar, and protruding from the surface of the skin, much like a hernia. The pathophysiology of an acquired digital fibrokeratoma is unknown. Trauma has often been proposed as a predisposing factor for ADFKs, but case histories have not supported this hypothesis. ${ }^{13,14}$ It is presumed that trauma or local factors result in an epidermal interaction and the development of fibroepithelial tumors. The lesions are usually dome-shaped, although they may present as elongated finger-like projections, as in our case. Herein, we report a case of giant acquired acral fibrokeratoma in a Saudi adolescent male.

\section{Case Report}

In April 2015, a 17-year-old Saudi male presented to the Dermatology Outpatient Clinic of Aseer Central Hospital, Aseer Region, Saudi Arabia, with a painless rounded skin-colored lump at the dorsum of his right middle toe. The tumor started four months earlier as a very small lesion, but slowly increased in size until it became a source of social embarrassment and personal inconvenience during wearing his shoes. The patient denied exposure to any associated direct trauma to the toes, and he did not receive any treatment for the lesion. Moreover, there were no similar skin lesions in the patient's family. By clinical examination, there was a skin-colored exophytic rounded nodule arising from the dorsal surface of the right middle toe, $1.7 \mathrm{~cm}$ in diameter (Figure 1). The patient did not have any other similar lesions. There were no associated chronic diseases or infections.

The tumor was surgically excised. Histopathology examination revealed a giant polyploid section, composed of massive hyperkeratosis, acanthosis, with a core of thick collagen bundles and vertically oriented small dermal blood vessels (Figure 2). Therefore, based on clinical and histopathological findings, the patient was diagnosed as a case of giant acquired acral fibrokeratoma. There was no evidence of recurrence for three years after surgical excision.
Correspondence: Hend M. Al-Atif, Department of Internal Medicine, College of Medicine, King Khalid University, Abha, Saudi Arabia.

Tel. +966555211366 .

E-mail: hmsalatif@yahoo.com

Key words: Acquired acral fibrokeratoma; Tumor; Skin lesion; Histopathology; Saudi Arabia.

Conflict of interest: the author declares no potential conflict of interest.

Funding: none.

Ethical statement: written informed consent was obtained from the patient for publication of this case report and accompanying images.

Received for publication: 21 June 2019.

Revision received: 30 September 2019.

Accepted for publication: 1 October 2019.

This work is licensed under a Creative Commons Attribution-NonCommercial 4.0 International License (CC BY-NC 4.0).

C Copyright: the Author(s), 2019

Licensee PAGEPress, Italy

Dermatology Reports 2019; 11:8215

doi:10.4081/dr.2019.8215

\section{Discussion}

Our patient was a Saudi male adolescent, who presented with a spontaneous, painless, solitary tumor at the right middle toe that has been progressively growing for the past four months to reach a relatively large size (more than one $\mathrm{cm}$ ). This presenting picture of AAF is by that reported by Baykal et al., ${ }^{15}$ who stated that AAF is almost always solitary, mostly seen in adults, with a slight male predominance. Despite being not painful or tender, AAF in our patient was a cosmetic problem and became more annoying to him while wearing shoes as it increased in size. This is in accordance with that reported by Bron et $a l .{ }^{5}$ who noted that $\mathrm{AAF}$ is more a cosmetically bothersome than a problematic lesion. However, patients with giant AAF on the dorsal surface of their foot may report some discomfort.

The patient denied any history of trauma to the toes associated with his tumor. Nevertheless, Jaiswal and Chatterjee ${ }^{16}$ noted that trauma seems to be a contributing factor to AAF. The diagnosis of our patient's lesion was based upon both clinical and histopathological findings. The 


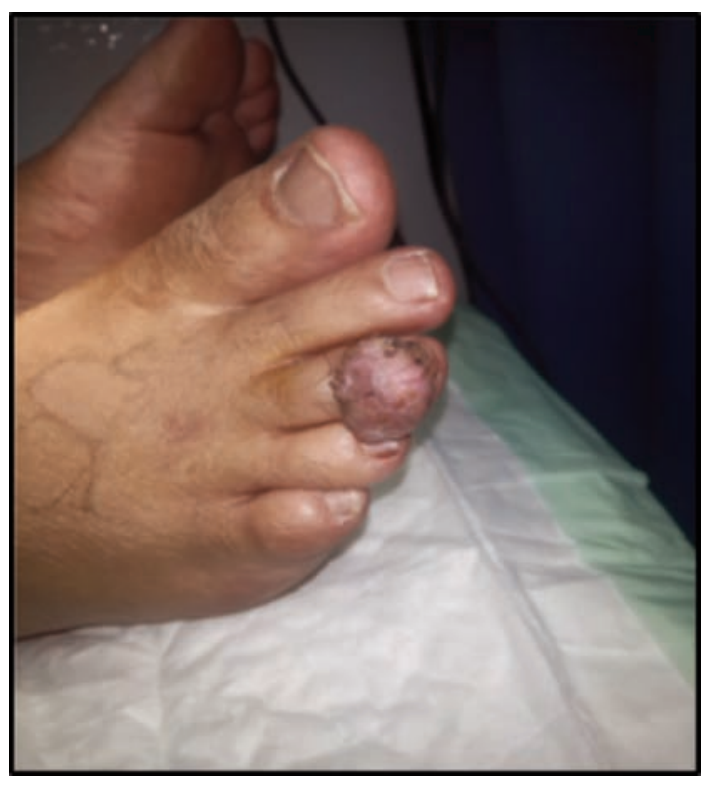

Figure 1. Light pink exophytic nodule arising from the dorsal surface of the right middle toe.

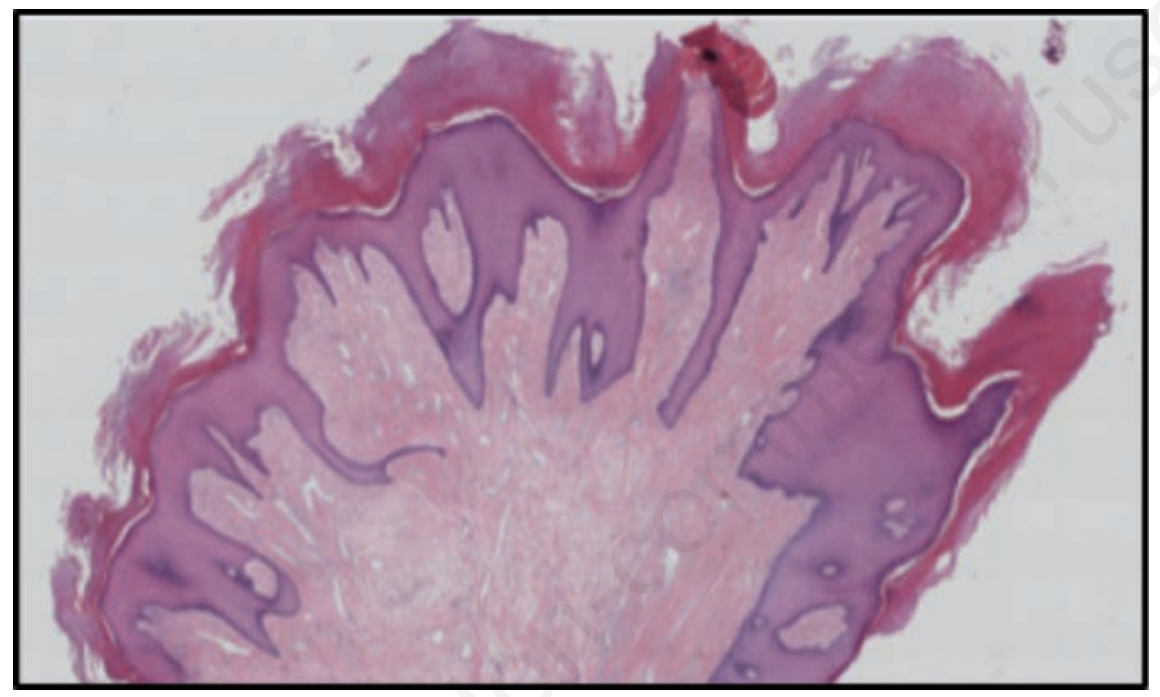

Figure 2. Histopathology of the skin lesion (Hematoxylin and Eosin, $\times 80$ ) showing a giant polyploid section composed of massive hyperkeratosis, acanthosis, core of thick collagen bundles and vertically oriented small dermal blood vessels.

lesion was treated by surgical excision, and no recurrence was observed within a follow-up period of three years.

Shih et al. ${ }^{17}$ stated that the diagnosis of AAF needs to be confirmed with an excisional biopsy since several conditions may clinically mimic AAF. Lee et al. ${ }^{18}$ added that the first line of treatment for AAF is surgical excision of the tumor, with very rare recurrence. To the best of our knowledge, this is the first reported case of acquired acral fibrokeratoma in Saudi
Arabia. Generally, this may be due to the rare incidence of $\mathrm{AAF}$, and also possibly due to the lack of awareness of primary care physicians regarding the diagnosis AAF, which should be differentiated from other skin tumors, particularly, fibroma, cutaneous horn, Koenen's tumor and eccrine poroma. ${ }^{16}$ Vinson and Angeloni ${ }^{19}$ stated that an important differentiating clinical characteristic of AAF is the presence of a collarette of slightly raised skin around the tumor.

\section{Conclusions}

In conclusion, $\mathrm{AAF}$ is a rare benign skin tumor which should be differentiated from other similar skin lesions. Awareness of primary care and family physicians should be raised toward the recognition and referral of patients with this tumor. Surgical excision is the first-line treatment of this benign tumor.

\section{References}

1 Ali M, Mbah CA, Alwadiya A, et al. Giant fibrokeratoma, a rare soft tissue tumor presenting like an accessory digit, a case report and review of literature. Int J Surg Case Rep 2015;10:18790.

2. Lu YY, Lu CC, Wu CH. Giant digital fibrokeratoma of the finger. Int $\mathrm{J}$ Dermatol 2013;53:205-7.

3. Boffeli TJ, Abben KW. Acral fibrokeratoma of the foot treated with excision trap door flap closure: a case report. J Foot Ankle Surg 2014;53:449-52.

4. Selmanowitz VJ. Acral fibrokeratoma. Int J Dermatol 1971;10:166.

5. Bron C, Noël B, Panizzon RG. Giant fibrokeratoma of the heel. Dermatology 2004;208:271-2.

6. Cho EA, Lee WS, Kim SY. A case of giant acquired digital fibrokeratoma resembling supernumerary digit. Kor J Dermatol 2007;45:319-20.

7. Lencastre A, Richert B. Flat-pan nailwide acquired epiungual fibrokeratoma: report of 4 cases. Skin Appendage Disord 2019;5:111-3.

8. Choi JH. Giant acquired digital fibrokeratoma occurring on the left great toe. Ann Dermatol 2011;23:64-6.

9. Tower DE, Hammond JR. Acral fibrokeratoma a rare pedal soft-tissue mass. J Am Podiatr Med Assoc 2018;108:1727.

10. Li S, Li X, Li F, Li B. Acquired digital fibrokeratoma: a case report and review of the literature. J Surg Dermatol 2017;2:75-9.

11. Frydman AF, Mercer SE, Kleinerman $\mathrm{R}$, et al. Acquired fibrokeratoma presenting as multiple plantar nodules. Dermatol Online J 2010;16:5.

12. Dupré A, Christol B, Bories M. Acquired fibro-keratoma. Report of 8 cases. Ann Dermatol Venereol 1977;104:611-5.

13. Kakurai M, Yamada T, Kiyosawa T, et al. Giant acquired digital fibrokeratoma. J Am Acad Dermatol 2003;48:S67-8. 
14. Kint A, Baran R, De Keyser H. Acquired (digital) fibrokeratoma. J Am Acad Dermatol 1985;12:816-21.

15. Baykal C, Buyukbabani N, Yazganoglu $\mathrm{KD}$, et al. Acquired digital fibrokeratoma. Cutis 2007;79:129-32.

16. Jaiswal AK, Chatterjee M. Acquired (digital) fibrokeratoma. Indian $\mathrm{J}$
Dermatol Venereol Leprol 2002;68: 179-80.

17. Shih S, Khachemoune A. Acquired digital fibrokeratoma: review of its clinical and dermoscopic features and differential diagnosis. Int $\mathrm{J}$ Dermatol 2019;58:151-8.

18. Lee CY, Lee KY, Kim KH, et al. Total excision of acquired periungual fibrokeratoma using bilateral proximal nail fold oblique incision for preserving nail matrix. Dermatol Surg 2010;36:139-41.

19. Vinson RP, Angeloni VL. Acquired digital fibrokeratoma. Am Fam Physician 1995;52:1365-7. 